\title{
The Influence of Gender Difference on the Information-seeking Behaviors for the Graphical Interface of Children's Digital Library
}

\author{
Tsia-ying Hsieh, Ko-chiu Wu ${ }^{*}$ \\ Department of Interaction Design, Nation Taipei University of Technology, Taiwan
}

Copyright (C) 2015 Horizon Research Publishing All rights reserved.

\begin{abstract}
Children conducting searches using the interfaces of library websites often encounter obstacles due to typographical errors, digital divides, or a failure to grasp keywords. Satisfaction with a given interface may also vary according to the gender of the user, making it a variable in information seeking behavior. Children benefit more from graphical information than text-based information with regard to learning. This study analyzed existing websites of public libraries to identify the issues facing children while using the interfaces. Based on these findings, we developed a graphical interface that children would find friendlier. In an evaluation of the proposed interface, girls presented a significantly higher success rate, compared to that of boys. We can therefore conclude that gender differences exist in the efficiency and effectiveness of the proposed interface. Qualitative observations also revealed gender differences in information seeking behavior, some principles of which are outlined in this study. Based on these findings, we present the following suggestions for libraries and future researchers: 1. Public libraries should establish websites with interfaces specifically designed for children; 2. Future researchers should take into account the gender differences associated with the operation of interfaces and information seeking behavior in the development of auxiliary information technologies; 3. Public libraries should consider creating interfaces specific for different age groups and genders.
\end{abstract}

Keywords Children's Library, Information Seeking Behavior, Graphical Interface, Cognitive Development Of Children, Gender Differences

\section{Introduction}

Children and adults differ considerably when it comes to information-searching behavior. Many studies have concluded that children are far more limited than adults with regard to information seeking capabilities. It would be reasonable to assume therefore that children could benefit greatly from an improved web interface designed specifically to help them overcome these barriers. Kulper et al. [1] discovered that most children aged 8-11 years are unable to perform searches based on the name of an author. Other difficulties are associated with the spelling or phrasing of search statements, applying the search terms used in official subject headings, narrowing search fields, and making use of Boolean expressions. Children also tend to stop searching after only a few hits. Bilal \& Kirby [2] discovered that the browsing style of children is loopy, while that of adults is more linear or systematic. Heather [3] reported that the greatest difficulties facing children in the search for information are operational barriers and a lack of skills associated with searching for information. The designers of online public access catalogs (OPAC) often overlook the limited vocabulary and immature search strategies of children, such that the resulting interface can act as an obstacle to children attempting to use the system.

In a study of 700 elementary school students, Solomon [4] found that their information needs generally originate from schoolwork or personal interests. Weng [5] identified schoolwork as the primary motive for seeking information on the internet, followed by entertainment and the acquisition of new knowledge. Most of their questions associated with information retrieval had to do with schoolwork, specifically social studies and science. In the acquisition of new knowledge, most of their questions concerned English and history. Many adults attribute the immature communication skills of children to a limited need for information; however, as shown above, this is simply not the case.

A number of studies have shown that graphical information is more beneficial than textual information in the promotion of learning by children. Many researchers have pointed out that the inclusion of pictures with text enhances learning effectiveness $[6,7,8]$. Wu, et al. [9] redesigned the interface of the digital resource website established by the National Library of Public Information (NLPI), by adding graphics to the original text-oriented interface and combining icon recognition with a two-dimensional visual 
interface. They found that this design increased the success rate and efficiency of operations.

Researchers have also investigated the influence of gender on information seeking behavior and patterns. Wilson [10] proposed that gender is an essential variable in information seeking behavior, and Passig \& Levin [11] observed that satisfaction with an interface may vary according to the gender of the user. Roy \& Chi [12] observed that girls and boys (14 participants: ages 13-14) differ in their search patterns when using the Web to find answers to specific questions. Boys tend to use horizontal search methods in which they iteratively submit searches and then scan the document snippets returned as search results. In contrast, Girls tend to employ vertical search methods in which they tend open and browse the web pages returned by the search engine without reviewing the list or filtering out irrelevant results. In the end, the strategy adopted by most boys tends to provide superior search performance.

Clearly, elucidating the information seeking behavior of children is important. This study selected a friendly, graphical search interface from a children's website, which was deemed suitable for elementary school students. We then examined the issues that children encounter in using the interface and performed qualitative observations and statistical analysis to characterize gender differences regarding the effectiveness with which the interface was used.

\section{Methods}

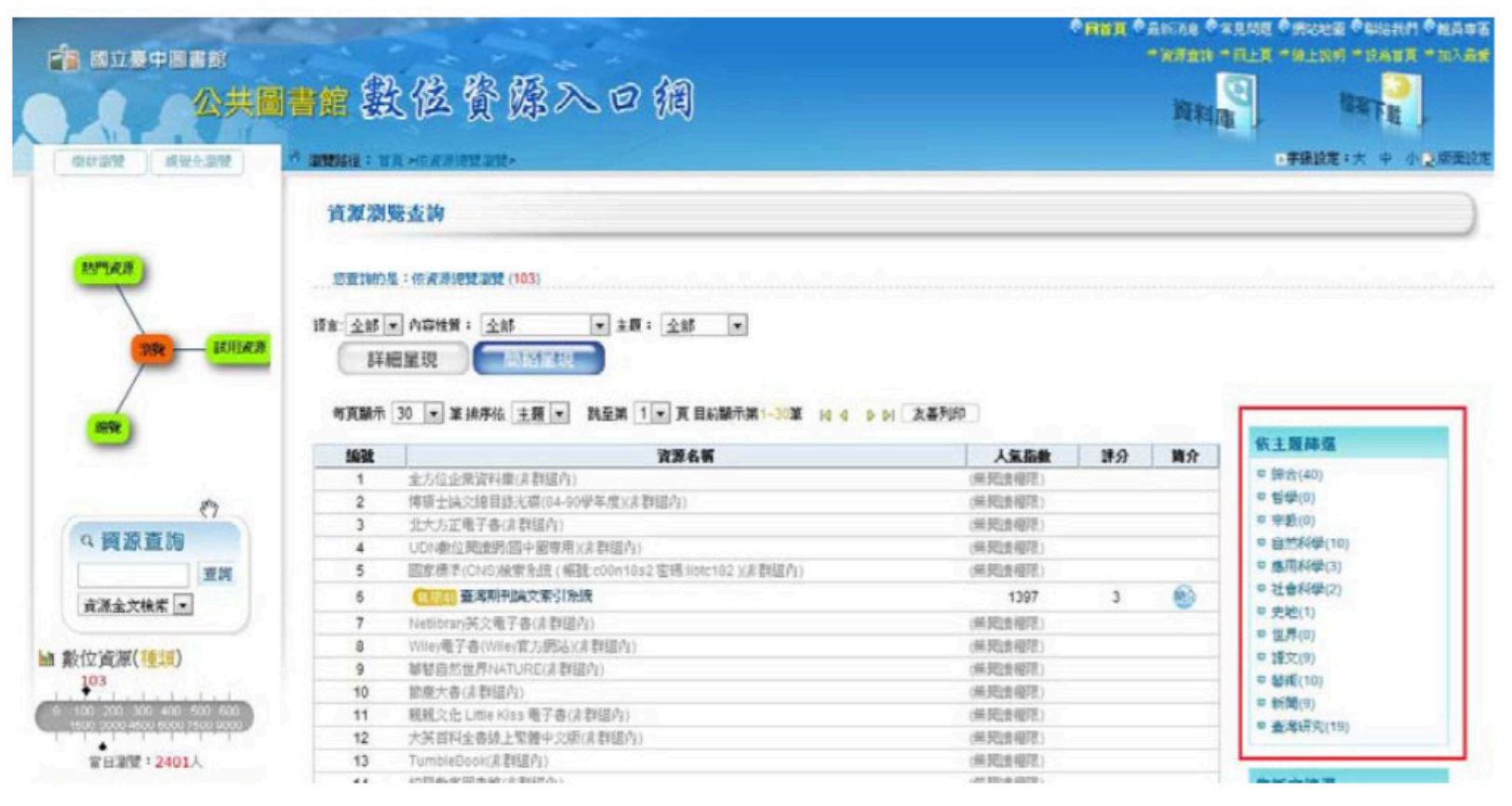

Figure 1. NLPI text-based interface

\subsection{Experiment Instrument: Graphical Interface for Children}

We began by analyzing existing websites of public libraries to identify the issues facing children in the use of their interfaces. Very few websites provide search interfaces specifically designed for children. For instance, the original interface of the portal to the NLPI (Fig.1) was mostly text, and the digital resources were categorized according to the Chinese Library Classification Scheme. However, numerous studies, including research on the International Children's Digital Library (ICDL), pointed out the need to design interfaces specifically for children to better accommodate their specific needs and cognitive development.

To deal with problems facing children in the use of this interface, Wu et al. [9] re-divided the NLPI database into five major categories: Natural Sciences, Fine Arts and Music, Health and Athletics, History and Culture, and Treasure of Knowledge. $\mathrm{Wu}$ et al.[9] produced an extensive two-dimensional virtual space interface based on pathfinding concepts, which prevents users from getting lost when searching for information through the inclusion of multi-level hyperlinks. The design of the interface used linked various icons to the various NLPI databases. This resulted in a graphical interface that was truly suitable for children (Fig. 2). They found that that when elementary school students used the new interface, their success rates and efficiency were significantly higher than those obtained from the original NLPI interface. In addition, the new graphical interface better complemented the information seeking behavior of children. We adopted this new graphical interface as the instrument in our experiment looking at gender differences in information seeking behavior.

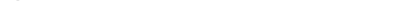




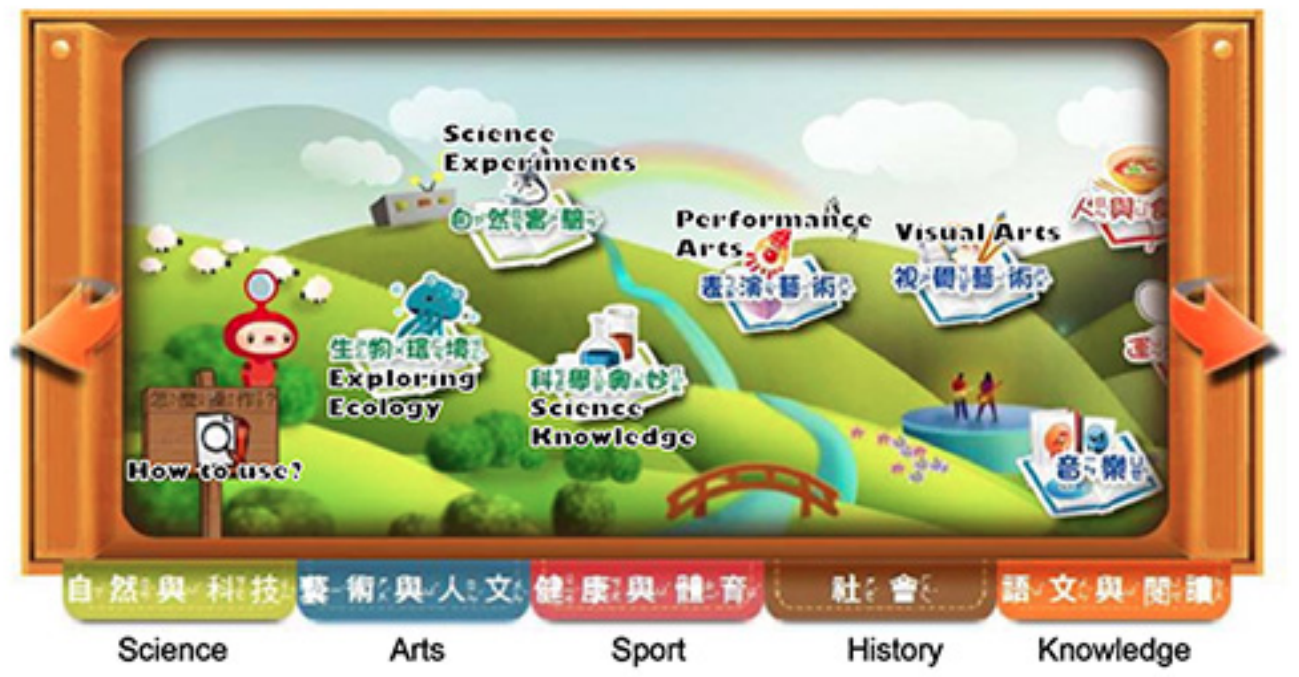

Figure 2. NLPI graphical interface for children's digital library

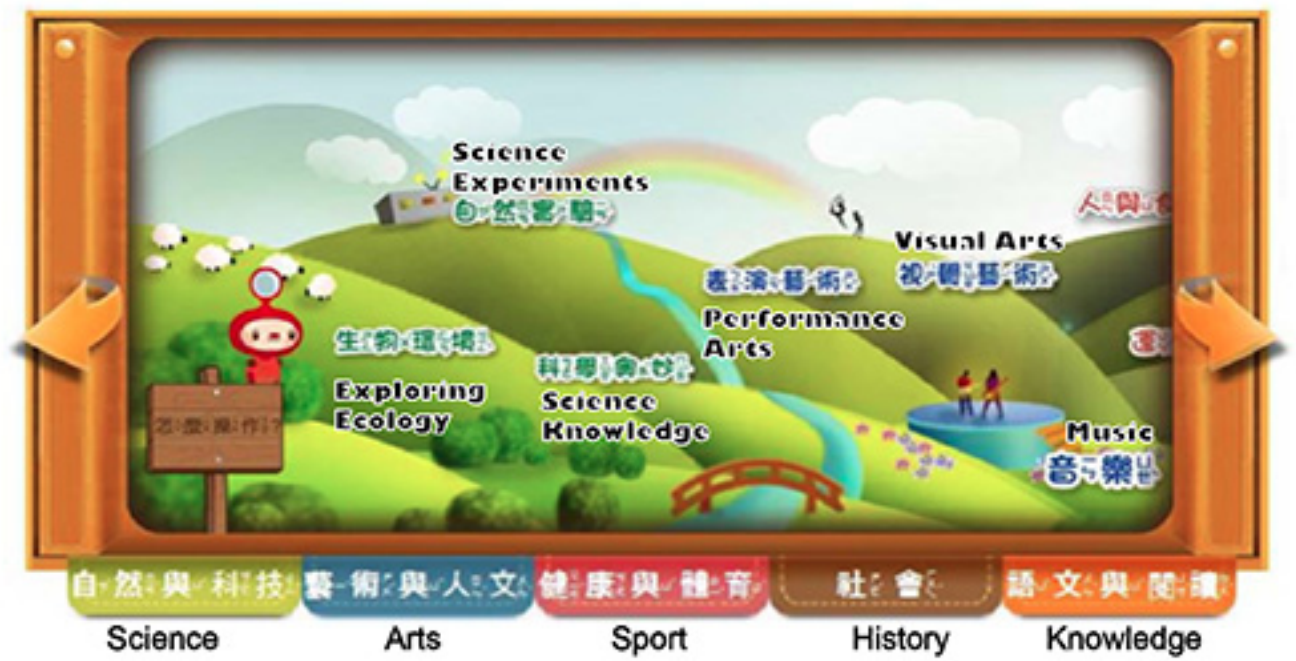

Figure 3. NLPI text-only interface for children's digital library

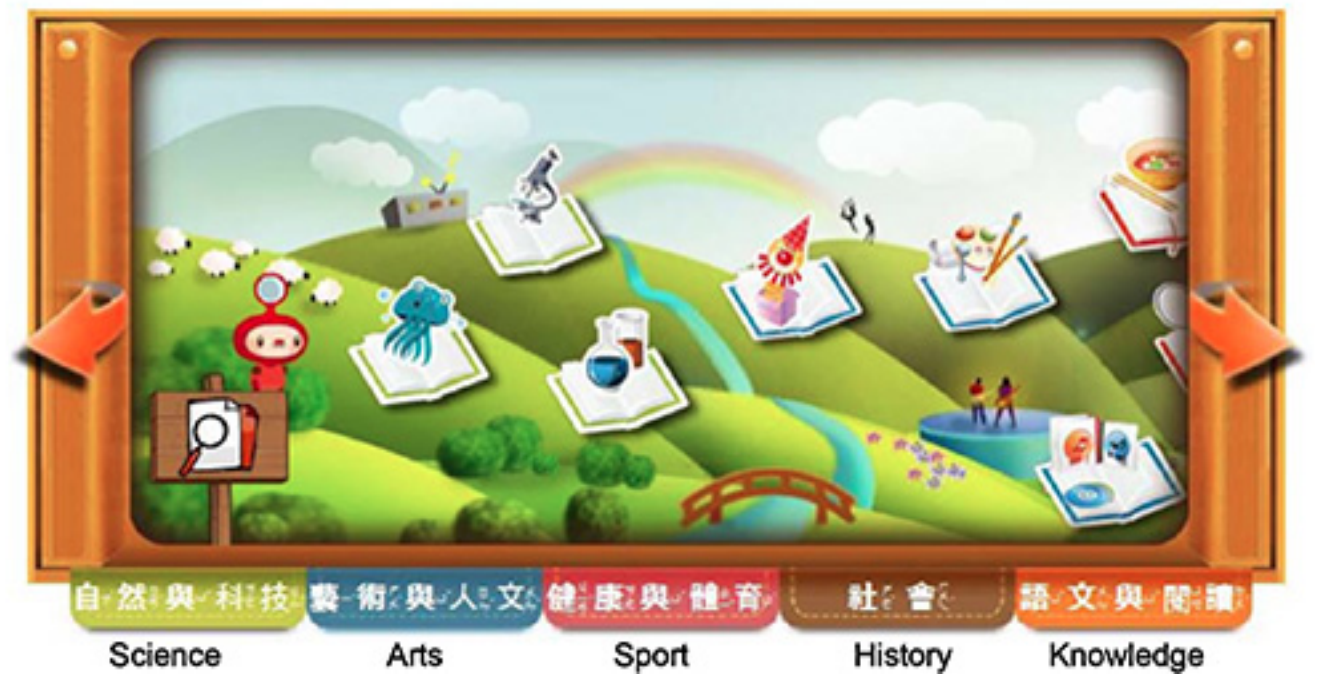

Figure 4. NLPI icon-only interface for children's digital library 


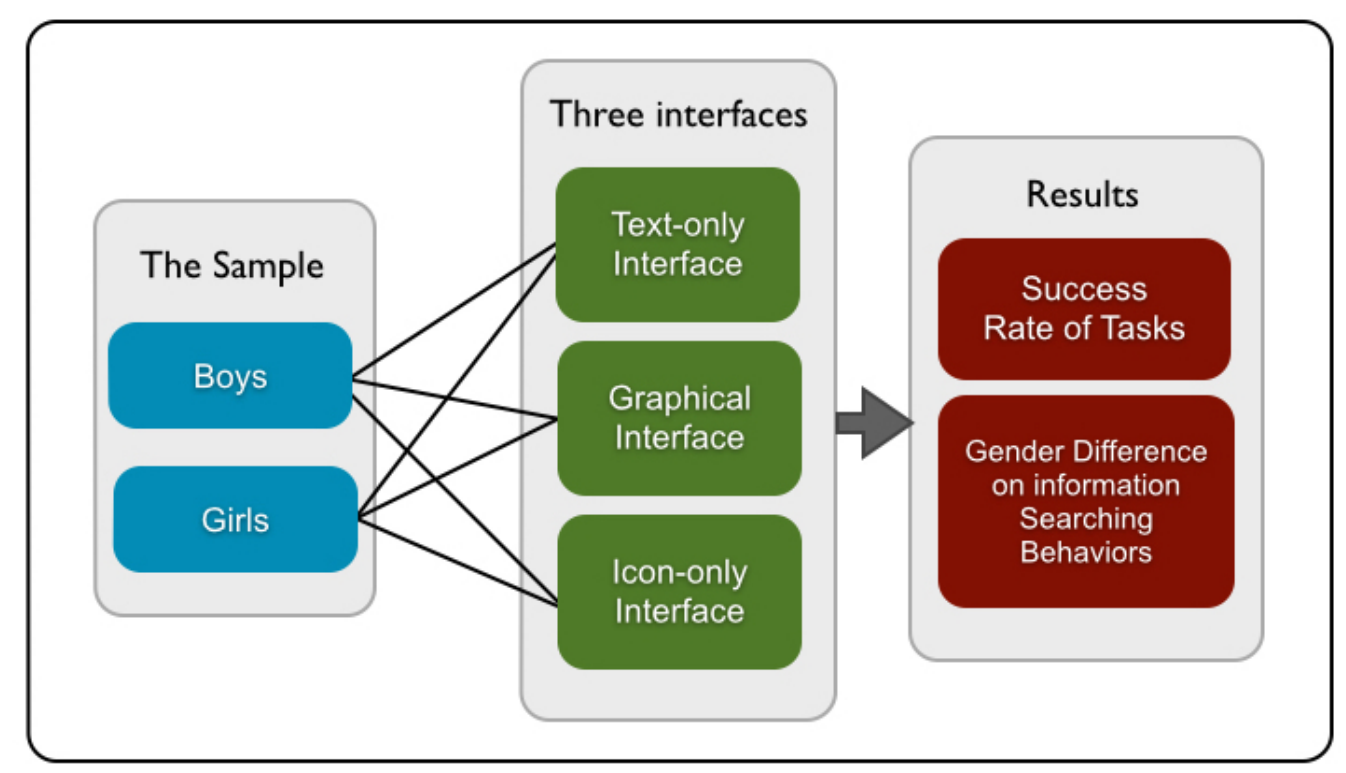

Figure 5. flowchart used in the experiment

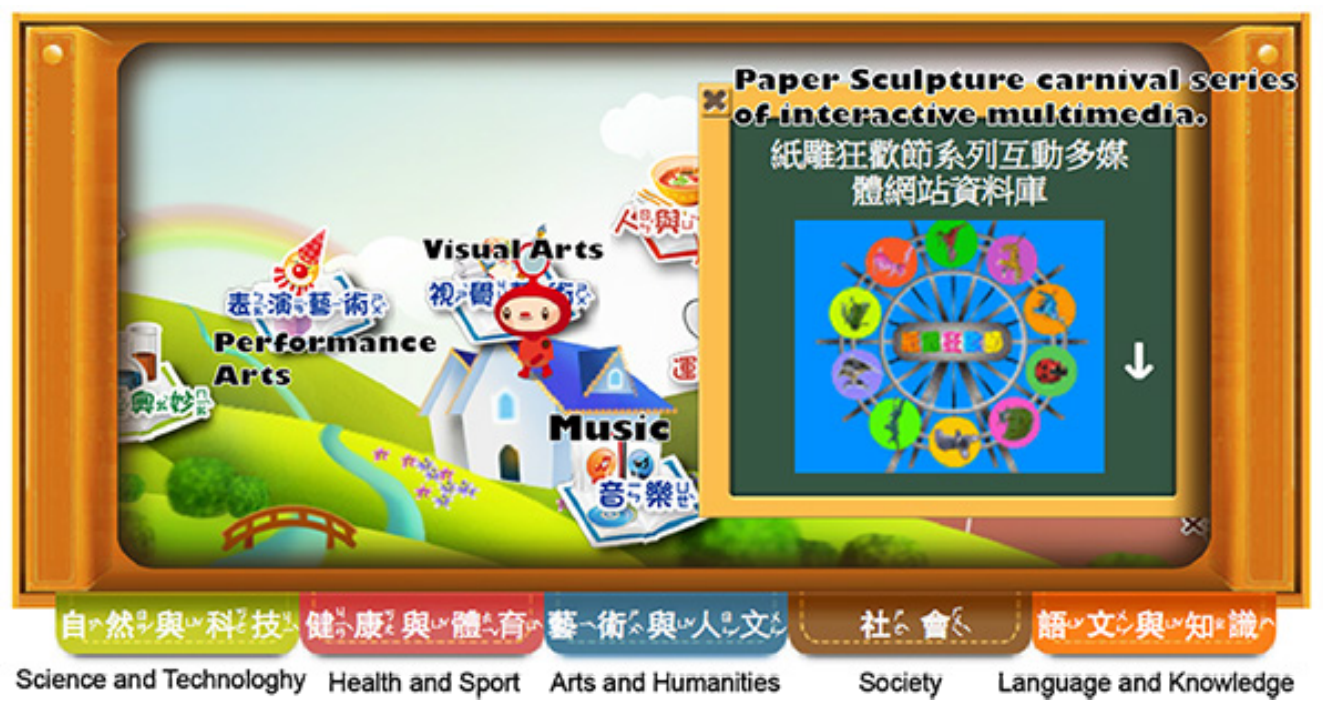

Figure 6. Graphical interface of children digital library showing a pop-up window

\subsection{Subjects and Experiment Procedure}

The subjects in this study were classes of elementary school students between the ages of 7 and 12 randomly selected from four municipal schools in Taipei City: Shuanglian Elementary, Changchun Elementary, Wanxing Elementary, and Changan Elementary (in the order that the experiments were conducted). A total of 296 participants were included in the sample. Details of participants in the sample are presented in Table 1.

As shown in Fig. 3, female and male participants were randomly divided into three groups, comprising 164,77 , and 77 subjects, respectively (Table1). The first group was asked to complete tasks using a graphical interface (Fig. 2), the second group performed tasks using a text-only interface (Fig. 3), and the third group used an icon-only interface (Fig. 4). Mouse movement patterns (the spaceman cursor) were observed to examine differences in information seeking behavior between the two genders. The rate of success in task completion was also recorded.

\begin{tabular}{lcccc} 
Table 1 Samples in Gender \\
\hline Gender & \multicolumn{4}{c}{ Task1 \& Task2 } \\
\cline { 2 - 5 } & Graphical interface & Icon-only interface & Text-only interface & $\begin{array}{c}\text { Total } \\
\text { N=296 }\end{array}$ \\
\hline Boys & 75 & 41 & 36 & 152 \\
& $(25.34 \%)$ & $(13.85 \%)$ & $(12.16 \%)$ & $(51.35 \%)$ \\
Girls & 71 & 36 & 37 & 144 \\
& $(23.99 \%)$ & $(12.16 \%)$ & $(12.5 \%)$ & $(48.65 \%)$ \\
Total & 146 & 77 & 73 & 296 \\
& $(49.33 \%)$ & $(26.01 \%)$ & $(24.66 \%)$ & $(100 \%)$ \\
\hline
\end{tabular}

The primary objective of this experiment was to determine whether gender plays a role in the use of the graphical interface of the children's digital library. The participants were assigned two tasks with different themes. Based on the 
findings of Weng [5], we assigned a search of information in the social studies domain as Task 1, and a search involving the acquisition of new knowledge related to extracurricular entertainment as Task 2.

In conducting searches, the students selected the icon associated with a given category by moving the spaceman cursor. Clicking the icon caused a small pop-up window to open providing additional details related to the content of that category, as shown in Fig. 6.The subjects were asked to notify the individuals conducting the experiment when they completed the task and to name the database they found. The experimenters recorded the time spent in completing the task.

The success rates and completion times recorded throughout the experiment were analyzed using SPSS to determine whether gender influenced the efficiency with which the interface was operated. We also documented the subjects as they completed their tasks using a digital camera and a computer screen recorder to qualitatively observe whether gender differences existed in graphical interface operation. Through image analysis, it was possible to observe how the male and female participants moved the spaceman cursor during the operation of the interface and whether they employed horizontal or vertical search patterns.

\section{Results}

\subsection{Influence of Gender on Completion of Tasks}

We used chi-square tests to compare the success rates of the subjects in the use of three types of interface in the completion of tasks as well as the amount of time required to accomplish this (searching for extracurricular information). The results indicated significant differences in the text-only interface $(* 0.02<0.05)$ (Table 2$)$ and in the graphical interface $(* 0.021<0.05)$ (Table 3$)$, whereas no significant differences were observed in the success rates in the other experiments. No significant differences were observed between the boys and girls with regard to the time required for the completion of tasks.

As shown in Table 2, using the text-only interface, girls had a success rate of $89.2 \%$, whereas boys had a success rate of $66.7 \%$. As shown in Table 3, using the graphical interface, girls $(97.2 \%)$ outperformed the boys $(86.7 \%)$.

Table 2 Comparison of success rates between boys and girls in text-only interface

\begin{tabular}{cccccc}
\hline \multicolumn{5}{c}{ Text-only interface } & $\begin{array}{c}\mathrm{N}=164 \\
\text { Significance }\end{array}$ \\
\cline { 1 - 3 } Boys & Number & Failure & Success & Success rate \\
Girls & 36 & 12 & 24 & $66.7 \%$ & $.020^{*}$ \\
\hline
\end{tabular}

${ }^{*} p<0.05,{ }^{* *} p<0.01$, ${ }^{* * *} p<0.001$

Table 3 Comparison of success rates between boys and girls in graphical interface

\begin{tabular}{|c|c|c|c|c|c|}
\hline \multicolumn{5}{|c|}{ Graphical interface } & \multirow{2}{*}{$\begin{array}{c}\mathrm{N}=164 \\
\text { Significance }\end{array}$} \\
\hline & \multicolumn{3}{|c|}{ Task2 } & & \\
\hline & Number & Failure & Success & Success rate & \\
\hline Boys & 75 & 10 & 65 & $86.7 \%$ & \\
\hline Girls & 71 & 02 & 69 & $97.2 \%$ & . 021 \\
\hline
\end{tabular}

\subsection{Influence of Gender on Information Seeking Behavior}

Gender differences were observed in the information seeking behavior of the participants. The boys cared a lot about the accessibility of information and tended to browse quickly and complete their task by clicking each icon and skimming through the contents haphazardly. In contrast, the girls attached more importance to information diagnosticity and searched more cautiously, pausing the cursor on the screen for greater lengths of time and only clicking on icons only when they thought it probably contained the information they were looking for. 


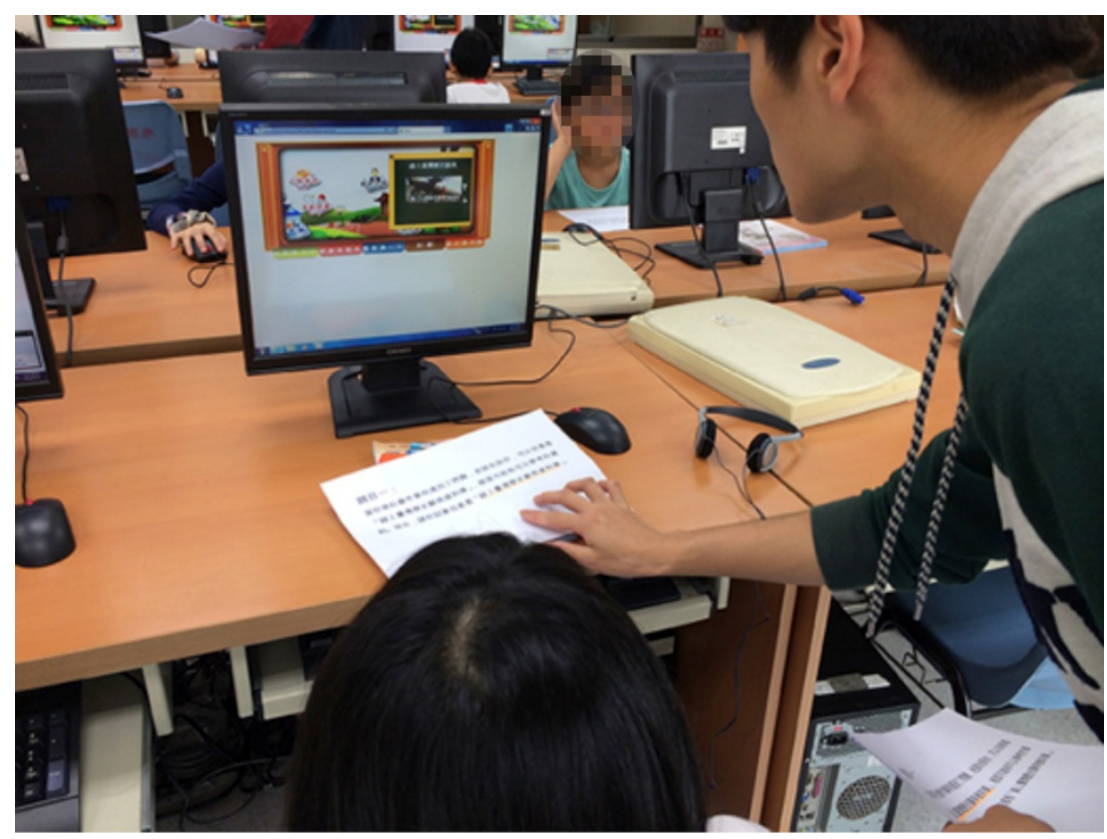

Figure 7. Children operating the graphical interface during the experiment

\section{Conclusions}

The objective of this study was to characterize gender differences in the information seeking behavior of children using child-friendly graphical interfaces. Our statistical results indicate that the success rates of girls using text-based and graphic-and-text interfaces were significantly higher than those of boys. We can therefore conclude that gender differences do exist in the operation of these interfaces. We infer that these results can be attributed to the superior linguistic capabilities of girls, as described by Maccoby \& Jacklin [13]. The vocabulary of elementary school students grows with age; however, the number of Chinese characters that girls have memorized at any given age is generally higher than that of boys [14]. These factors likely contributed to the differences in performance between male and female students in these tests. Furthermore, this study was limited to the websites of public libraries. It is hoped that further research will be conducted using other websites.

Qualitative observation also revealed gender differences in information seeking behavior. Observation of the interface operations revealed results similar to those reported by Bilal and Kirby (2002) [2], in which children were using an unfamiliar interface. Boys were more likely than girls to employ a loopy browsing style in which their line of vision repeatedly swept back and forth across web pages. In addition, the subjects were easily distracted by objects of interest despite attempts to complete assigned tasks. We also observed boys tend to use horizontal search methods, whereas girls employ vertical search methods.

Based on these findings, we present the following suggestions for libraries and future researchers: 1. the linguistic skills of girls in elementary school tend to be superior to those of boys; therefore, we recommend the inclusion of more textual elements in future interface designs in order to assist girls in seeking for information. Likewise, more graphical elements should also be used to assist boys in their information seeking efforts. 2. Public libraries should establish websites with interfaces specifically designed for children; 3. Future researchers should take into account the gender differences associated with the operation of interfaces and information seeking behavior in the development of auxiliary information technologies; 4. Public libraries should consider creating interfaces specific for different age groups and genders.

\section{REFERENCES}

[1] Kulper, U., Schulz, U. \& Will, G. (1997). Bucherschatz - A prototype of a children's OPAC. Information Services \&Use, 01675265, 17(2/3), 201-214.

[2] Bilal, D., \& Kirby, J. (2002). Differences and similarities in information seeking: children and adults as Web users. Information Processing \& Management, 38(5), 649-670.

[3] Heather, P. (1984). Research on Information Skills in Primary Schools. Center for Research on User Studies, University of Sheffied.

[4] Solomon, P. (1993). Children's information retrieval behavior: A case analysis of an OPAC. Journal of the American Society for Information Science, 44(5), 245-264.

[5] Weng, W. C. (2003). An Empirical Study of Senior Grades of Elementary School Students-Web Information Seeking Behavior. (Master's thesis). Available from National Digital Library of Theses and Dissertations in Taiwan.

[6] Levin, J. R. (1981). On the functions of pictures in prose. In F. J. Pirozzolo \& M. C. Wittrock (Eds.), Neuropsychological and cognitive process in reading (203-228). San Diego: Academic Press. 
[7] Levie, W. H., \& Lentz, R. (1982). Effects of text illustrations: A review of research. Educational Technology Research and Development, 30(4), 195-232.

[8] Levin, J. R., Anglin, G. J. \& Carney, R. N. (1987). On empirically validating functions of pictures in prose. In D. C. Willows \& H. A. Houghton (Eds.), The psychology of instruction. Vol.1 (55-58). NY: Springer.

[9] Wu, K. C., Tang, Y. M., \& Tsai C. Y. (2014). Graphical interface design for children seeking information in a digital library. Visualization in Engineering, 2(5), doi: 10.1186/2213-7459-2-5.

[10] Wilson, T. D. (1997). Information behavior: an interdisciplinary perspective. Information Processing \&
Management, 33(4), 551-572.

[11] Passig, D. \& Levin, H. (2000). Gender preferences for multimedia interfaces. Journal of Computer Assisted Learning, 16(1), 64-71

[12] Roy, M. \& Chi, M. (2003). Gender differences in patterns of searching the web. Journal of Educational Computing Research, 29(3), 335-348.

[13] Maccoby, E. \& Jacklin, C. N. (1974). The Psychology of Sex Differences Stanford, London: Oxford University Press.

[14] Wang, C. C., Hung, L. Y., Chang, Y. W., \& Chen, H. F. (2008). Number of Characters School Students Know from Grade 1 to G9. Bulletion of Education Psychology, 39(4), 555-568. 